\title{
LV. On the peculiar voltaic condition of iron
}

\section{Henry Minchin Noad Esq.}

To cite this article: Henry Minchin Noad Esq. (1837) LV. On the peculiar voltaic condition of iron, Philosophical Magazine Series 3, 10:61, 276-278, DOI: 10.1080/14786443708649139

To link to this article: http://dx.doi.org/10.1080/14786443708649139

册 Published online: 01 Jun 2009.

Submit your article to this journal 준

Џ Article views: 2

Q View related articles $₫$ 
that of a current the relation of cause to effect, or, generally speaking, that voltaic electricity is due to chemical action and by no means to contact.

I am quite confident that inactive iron can be used in a great number of cases for obtaining results similar to that just spoken of, and that the peculiar state of this metal offers to philosophers in many other respects a most valuable means for making electro-chemical researches.

Bâle, October 1836.

LV. On the peculiar Voltaic Condition of Iron. By H. M. Noad, Esq.

\section{To the Editors of the Philosophical Magazine and Journal.}

Gentlemen,

THE singular phænomena presented by iron when put under certain circumstances into nitric acid, which have been so well described in your Magazine by Professor Schœnbein, and for which Dr. Faraday has, with his usual ability, offered an explanation, had such an interest with me that I was induced to repeat all the experiments which have been described in your Journal; and in the course of these I was led to make other observations, which if you think worth while I shall feel obliged by having inserted in your next publication. When a wire that was made inactive by platina was dipped into a vessel of nitric acid, sp. gr. 1.374, and connected with the galvanometer, and a common iron wire, forst connected with the galvanometer, and then dipped into the acid, no action either electrical or chemical took place; but if it was put into the acid first there was always strong action, and the needle was deflected in the same manner as if the second wire was zinc and the first platina; action was then generally communicated for a moment to the first wire, and afterwards both wires were brought to the peculiar state and the needle was of course quiescent : if now either wire was touched in the acid with a common iron or copper wire, it was thrown into action, and the galvanometer was affected, the active wire playing the part of zinc. If instead of an inactive wire in this experiment a piece of platina was used, the moment the circuit was closed and the second wire was in action, bubbles of gas made their appearance on the platina; and if a common iron wire, round which a small piece of platina foil was wrapped, was substituted for the platina wire, these bubbles rose rapidly from all parts of the foil, but not one appeared on the 
iron; but when the foil was slipped off from the iron the gas then rose from the iron and continued to do so, but the metal was not thrown into action.

When two glasses were filled with acid and connected by a compound platina and iron wire, the platina or inactive iron in one glass exerted a protecting influence on the iron in the other, provided the communication was first made through the galvanometer: a touch, however, with a common iron wire threw the metal into action, producing a strong electrical current. The same was the case when three or four glasses connected by a compound platina and iron wire were employed.

But the most curious fact that I observed was this: the nitric acid was diluted with water till it had a sp. gr. of 1.204. In this acid iron was not protected by platina even when coiled thickly round it; on the contrary, it appeared to me that oxidation took place with increased rapidity when the platina was in connection. Neither was the iron protected when the connection between the metals was made through the medium of the galvanometer, provided that the iron was dipped into the acid first; but if the metal was first connected with the galvanometer and then put into the acid, no action whatever ensued in any length of time, even after the platina was removed: but once touching it with another piece of iron always threw it into action, it becoming instantly covered with a brown nitrate of iron; the wire thus made inactive did not possess the power of rendering other wire so, but was always thrown itself into action when common iron wire was substituted for the platina, whether it was connected with the galvanometer first or not. The first wire in this case acted as platina and the second as zinc with regard to the electrical effect that was for the moment produced.

When two cups were used in this experiment and the connection between them made by a bent common iron wire the result was the same, the platina in one cup protecting the iron in the second. The conditions before mentioned being observed, if now the inactive wire was made active, electrical action was produced, the current being conveyed across the connecting wire. Things being in this state, if the connecting wire was removed electrical action ceased; and if a fresh wire was bent, and one end first dipped into the cup containing the active wire, and then the other end put into the cup containing the platina, that end was immediately in the peculiar state. Now here there was no metallic connection whatever between this wire and platina, still it was preserved inactive, and there was also no passage for the electrical current, for the needle of the galvanometer was quite still; but when by touching with 


\section{$278 \mathrm{Mr}$. Brooke on the Intersection of Crystalline Minerals.}

a copper or iron wire it was made active, then there was passage for the current, and the needle was strongly deflected. From this it appears that when iron is in the peculiar state it is incapable of conducting a current of voltaic electricity. I have one more remark to make, which is, when the iron wire was inactive it was found impossible to make either end of the connecting wire so; and if the platina was removed from its cup and a common wire put in its place, it always made the wile in the other cup active.

I forbear to make any observations on the cause of these remarkable phænomena, as the matter is already in such able hands that it would be presumptuous for me to attempt to offer an opinion; trusting, however, that what I have noticed may be the means of inciting further researches,

$$
\text { I am, Gentlemen, yours, \&c., }
$$

Shawford, near Bath, March 14, 1837. Henry Minchin Noad.

LVI. On the Intersection of Crystals belonging to different Minerals in a regular and constant manner. By $\mathrm{H}$. J. Brooke, Esq., F.R.S., \&c.**

$\mathrm{N}$ examining lately some specimens of Chabasie from Ireland, I have observed several crystals penetrated by crystals of Gmelinite, with their axes in all instances parallel to those of the rhomboids of Chabasie, and the planes also corresponding in position with those of the Chabasie, as shown in the annexed figure. Sometimes the face of the Chabasie is covered by a single crystal of Gmelinite, and sometimes it is studded with many small ones.

The inclination of the plane $\mathbf{P}$ of Chabasie on the axis is $38^{\circ} 34^{\prime}$, and that of plane $g$ of Gmelinite $50^{\circ}$, whence the inclination of $g$ on $\mathrm{P}$ is $11^{\circ} 26^{\prime}$. This position is constant in all the crystals I have seen.

I am not aware of any analogous fact having been before noticed, and on looking over my own minerals, I observe only two other instances of the same

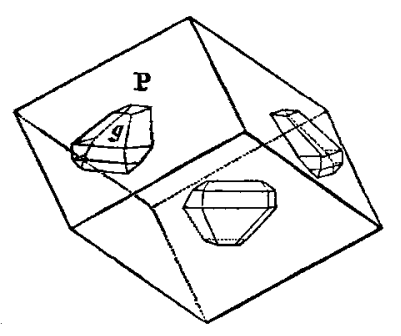
kind.

One is the combination of Oligiste iron and Rutile. If we suppose a summit of a rhomboid of Oligiste iron replaced by a triangular plane at right angles to the axis, and crystals

* Communicated by the Author. 